Old Dominion University

ODU Digital Commons

Mechanical \& Aerospace Engineering Faculty

Publications

Mechanical \& Aerospace Engineering

2020

Evaluation of the Mechanical Properties of Germanium-on-

Insulator (GeOl) Films by Raman Spectroscopy and

Nanoindentation

Y.S. Mohammed

Old Dominion University

Kai Zhang

S. Heissler

H. Baumgart

Old Dominion University

A. A. Elmustafa

Old Dominion University

Follow this and additional works at: https://digitalcommons.odu.edu/mae_fac_pubs

Part of the Electrical and Computer Engineering Commons, and the Mechanical Engineering Commons

Original Publication Citation

Mohammed, Y. S., Zhang, K., Heissler, S., Baumgart, H., \& Elmustafa, A. A. (2020). Evaluation of the mechanical properties of germanium-on-insulator ( $\mathrm{GeOl}$ ) films by Raman spectroscopy and nanoindentation. Journal of Applied Physics, 128(6), 1-7, Article 065104. https://doi.org/10.1063/ 5.0013454

This Article is brought to you for free and open access by the Mechanical \& Aerospace Engineering at ODU Digital Commons. It has been accepted for inclusion in Mechanical \& Aerospace Engineering Faculty Publications by an authorized administrator of ODU Digital Commons. For more information, please contact digitalcommons@odu.edu. 


\section{Evaluation of the mechanical properties of germanium-on-insulator (GeOl) films by Raman spectroscopy and nanoindentation}

Cite as: J. Appl. Phys. 128, 065104 (2020); https://doi.org/10.1063/5.0013454

Submitted: 11 May 2020 . Accepted: 26 July 2020. Published Online: 12 August 2020

Y. S. Mohammed, Kai Zhang, S. Heissler, (D) H. Baumgart, and (iD A. A. Elmustafa
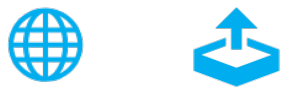

\section{ARTICLES YOU MAY BE INTERESTED IN}

A planar metamaterial based on metallic rectangular-ring pair for narrow electromagnetically induced transparency-like effect

Journal of Applied Physics 128, 065105 (2020); https://doi.org/10.1063/5.0012575

Molecular dynamics simulation of the diffusion of self-interstitial atoms and interstitial loops under temperature gradient field in tungsten

Journal of Applied Physics 128, 065103 (2020); https://doi.org/10.1063/5.0005505

Significant enhancement of near-field radiative heat transfer between black phosphoruscovered hyperbolic metamaterial

Journal of Applied Physics 128, 065109 (2020); https://doi.org/10.1063/5.0012878

Meet the Next Generation of Quantum Analyzers And Join the Launch Event on November 17th

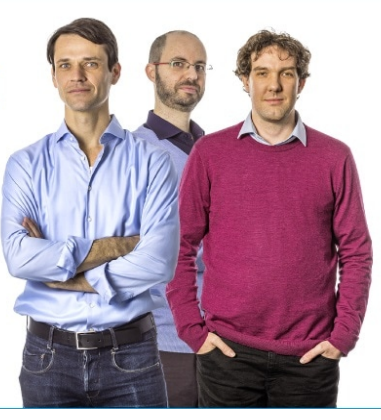

\section{Register now}

Zurich $\checkmark$ Instruments 


\title{
Evaluation of the mechanical properties of germanium-on-insulator (GeOl) films by Raman spectroscopy and nanoindentation
}

Cite as: J. Appl. Phys. 128, 065104 (2020); doi: 10.1063/5.0013454

Submitted: 11 May 2020 . Accepted: 26 July 2020 .

Published Online: 12 August 2020

Y. S. Mohammed, ${ }^{1,2}$ Kai Zhang, $^{2}$ S. Heissler, ${ }^{3}$ H. Baumgart, ${ }^{2,4}$ (D) and A. A. Elmustafa ${ }^{1,2, a)}$ (iD)

\begin{abstract}
AFFILIATIONS
${ }^{7}$ Department of Mechanical and Aerospace Engineering, Old Dominion University, Norfolk, Virginia 23529, USA

${ }^{2}$ Applied Research Center, Thomas Jefferson Lab, Newport News, Virginia 23606, USA

${ }^{3}$ Karlsruhe Institute of Technology (KIT), Institute of Functional Interfaces - (IFG), D-76344 Eggenstein-Leopoldshafen, Germany

${ }^{4}$ Department of Electrical and Computer Engineering, Old Dominion University, Norfolk, Virginia 23529, USA
\end{abstract}

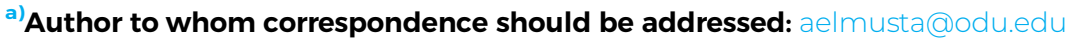

\begin{abstract}
Germanium-on-insulator (GeOI) films fabricated using the Smart Cut ${ }^{\mathrm{TM}}$ wafer bonding and film exfoliation technology were investigated for the mechanical properties and induced phase transformations by using nanoindentation and Raman spectroscopy experiments. The hardness and modulus results of the GeOI films are significantly different from the literature published Silicon-on-Insulator and bulk germanium results. The GeOI films are softer and more flexible as compared to bulk Ge hardness and stiffness properties. The Raman spectroscopy of the spherical indents indicates bands of metastable Ge phases @ $220 \mathrm{~cm}^{-1}, 195 \mathrm{~cm}^{-1}$, and $184 \mathrm{~cm}^{-1}$ wavenumbers. Our results demonstrate that a spherical indenter impacted a wider area of contact and produced GeOI indented surfaces free of cracks and fracture. The spherical indenter tip kept the Ge top layer intact when compared to the Berkovich indenter tip during penetration. In contrast, the Berkovich indenter tip developed excessive fracture that resulted in displacing the Ge top layer sideways and exposed the $\mathrm{Si}$ substrate underneath revealing Raman spectra bands of metastable Si phases @ $350 \mathrm{~cm}^{-1}, 399 \mathrm{~cm}^{-1}$, and $430 \mathrm{~cm}^{-1}$.
\end{abstract}

Published under license by AIP Publishing. https://doi.org/10.1063/5.0013454

\section{INTRODUCTION}

Silicon-on-insulator (SOI) is envisaged as a better alternative to bulk silicon due to its superb performance, less power consumption, and prevention of latch-up. The SOI technology was developed in the 1990s and enabled advanced CMOS devices that delivered among many advantages high speed and radiation hardness and constitutes a significant improvement over the older Silicon-on-Sapphire (SOS) technology. The fabrication of SOI and strained Silicon-onInsulator (sSOI) is accomplished using the Smart Cut ${ }^{\mathrm{TM}}$ wafer bonding technology utilizing high dose hydrogen implantation and a subsequent annealing process to effect layer splitting and film exfoliation. ${ }^{1}$ The strained sSOI technology was specifically developed for high mobility channel devices. ${ }^{2-4}$ It is not economically feasible to fabricate Ge bulk wafers to compete with bulk Si wafers due to the much higher production costs and more than twice the density resulting in heavier wafers for identical size plus poor mechanical strength. By extending the Smart Cut ${ }^{\mathrm{TM}}$ technology approach to germanium, the successful fabrication of germanium-on-insulator (GeOI) wafers proved to be the best choice material for Si-based photodetection. $\mathrm{Si}$ is transparent for telecommunication wavelengths $(\lambda>1.2 \mu \mathrm{m})$, which makes Si not suitable for wavelengths larger than $1.2 \mu \mathrm{m}$ for photodetection. On the other hand, Ge possesses a strong linear absorption of up to $1.55 \mu \mathrm{m}$, a strong compatibility with the mainstream planar Si complementary metal oxide semiconductor (CMOS) process technology in microelectronics, and Ge is considered an indirect bandgap material. ${ }^{5,6}$ Also, an important application of Ge is found in the fabrication of photodetectors on $\mathrm{Si}^{7,8}$ As an additional benefit, Ge retains a much higher carrier mobility as compared to $\mathrm{Si}$ which promises faster operation. A comparison between the electrical properties of $\mathrm{Ge}$ and $\mathrm{Si}$ reveals a critical advantage of nearly three times the electron mobility, $\mu_{\mathrm{e}}$ of $3900 \mathrm{~cm}^{2} / \mathrm{V} \mathrm{s}$ in Ge vs $1350 \mathrm{~cm}^{2} / \mathrm{V} \mathrm{s}$ in $\mathrm{Si}$, while the Ge hole mobility, $\mu_{\mathrm{h}}$ is $1900 \mathrm{~cm}^{2} / \mathrm{V} \mathrm{s}$ vs $480 \mathrm{~cm}^{2} / \mathrm{V} \mathrm{s}$ 
in Si enabling better devices and near infrared detectors. Although the lattice mismatch parameter between $\mathrm{Ge}$ and $\mathrm{Si}$ is large, i.e., $4.2 \%$, pseudomorphic epitaxial growth of strained crystalline SiGe alloy films on $\mathrm{Si}$ can be accomplished. However, attempting to grow $\mathrm{Ge}$ films directly on Si substrates with such a large lattice constant difference comes at the price of lattice defects, in particular, misfit dislocation networks to accommodate the interfacial strain. This drawback of a highly defective interface resulting from epitaxial growth of $\mathrm{Ge}$ on $\mathrm{Si}$ substrates has been limiting the application potential of $\mathrm{Ge}$ grown on Si substrates. However, this serious disadvantage can be completely eliminated with the Smart Cut ${ }^{\mathrm{TM}} \mathrm{GeOI}$ technology, which enables marrying dissimilar single crystal semiconductor materials without incurring any misfit dislocations or any other lattice defects. Additionally, GeOI saves Ge single crystal substrate cost, since only a thin single crystal Ge film is exfoliated from a bulk Ge wafer, and $\mathrm{GeOI}$ provides improved mechanical stability as compared to the fragile and heavy Ge bulk substrates. ${ }^{9}$ The Ge thin films resulting from the exfoliation of a bulk Ge wafer using the Smart Cut ${ }^{\mathrm{TM}} \mathrm{GeOI}$ technology produced Ge thin films with enhanced mechanical properties in comparison to the bulk Ge wafer.

Due to the interest in high mobility channel metaloxide-semiconductor field-effect transistor (MOSFET) devices, there are many literature studies on electrical properties of SiGe strained channels and GeOI devices, but very little is known about their nanomechanical properties. The current known literature background on mechanical properties can be outlined in the following section. Group IV elemental semiconductors, e.g., Si and $\mathrm{Ge}$, are considered brittle materials due to the high Peierls energy of the dislocations. ${ }^{10}$ Minomura and Drickamer, reported that under high pressures, $\mathrm{Si}$ and $\mathrm{Ge}$ reveal interesting properties. ${ }^{11}$ They observed that under a compressive pressure of 20 and $12 \mathrm{GPa}$, the electrical resistivity of $\mathrm{Si}$ and Ge dropped five orders of magnitude with a concomitant increase in electrical conductivity. Ge is a semiconductor material with a diamond cubic crystal structure that is covalently bonded. Under high pressures, Jamieson observed that Ge exhibits a $\beta$-Sn structure polymorph which is considered the phase that is responsible for metallic conductivity. ${ }^{12}$ Kiran et al. concluded that for diamond cubic germanium (dc-Ge), plastic deformation due to slip and twinning under the indenter tip might be responsible for a compromise in phase transformation. ${ }^{13}$ It might still experience phase transformation to the $\beta-S n-G e$ phase at high loading rates. However, the amorphous Ge (a-Ge) phase can easily undergo phase transformation over a wide range of indentation conditions because slip and twinning are probably irrelevant. ${ }^{13}$ Multiple studies also indicated that there is compelling evidence that phase transformation takes place in crystalline $\mathrm{Ge}$ subjected to indentation. ${ }^{14-18}$

Although Miller et al. studied the nanomechanical properties of multiple thin films of SOI and sSOI and reported that the hardness and moduli values of the SOI and sSOI are significantly different from known bulk Si values, ${ }^{19}$ no studies exist that discuss the mechanical properties of the GeOI films to the best of our knowledge.

In this work, we investigated using nanoindentation and Raman Spectroscopy the mechanical properties and induced phase transformation of the $\mathrm{GeOI}$ wafers focusing on the top defect-free single crystal $\mathrm{Ge}$ film bonded via a buried $\mathrm{SiO}_{2}$ oxide of

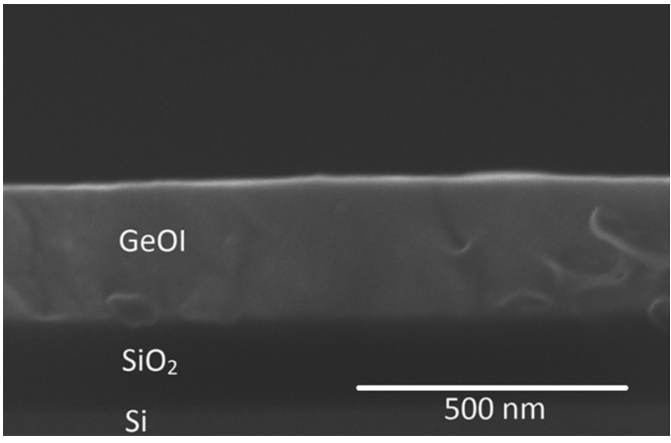

FIG. 1. Field emission scanning electron microscopy (FESEM) image of $\mathrm{GeOI}$ film on Si.

approximately $175 \mathrm{~nm}$ thickness to the $\mathrm{Si}$ substrate with the Smart Cut ${ }^{\mathrm{TM}}$ technology and film exfoliation technology. Single crystal Ge films on insulating oxide of 100, 220, 250, and $290 \mathrm{~nm}$ Ge thickness of (100) orientation were fabricated using the Smart Cut ${ }^{\mathrm{TM}}$ technology and tested for the structural and mechanical properties. The structural properties and morphology were explored using field emission scanning electron microscope (FE-SEM). The Ge film thickness of GeOI samples was verified using cross-sectional field emission scanning electron microscopy (FESEM) as shown in Fig. 1.

The nanomechanical properties were measured using nanoindentation to determine the modulus and hardness of the GeOI films. The induced nanoindentation experiments produced phase transformation in the Ge films. We used Raman micro-spectroscopy in order to examine and monitor the induced pressure and phase transformation in Ge films.

\section{EXPERIMENTAL TESTING}

The nanoindentation testing was carried out using an XP Nanoindenter tester from Agilent Technologies equipped alternatively with either a three-sided diamond Berkovich indenter tip with a maximum displacement of up to $2 \mu \mathrm{m}$ or with a spherical indenter. The XP indenter head was used in a continuous stiffness (CSM) mode. Constant displacement indentations in a CSM mode of $10 \%$ of the film thickness to circumvent substrate effects were performed on each film to study the films' properties. The CSM technique produces the evolution of hardness and elastic modulus as continuous functions of penetration depth into the surface by superimposing a small harmonic force oscillation (usually resulting in a harmonic displacement oscillation of $1 \mathrm{~nm}$ or less) on the tip during the loading cycle. This allows the stiffness of contact, and subsequently the mechanical properties of the sample to be continuously evaluated by analyzing the harmonic force and harmonic displacement data, as detailed elsewhere. 9 Prior to the measurements, the tip was calibrated using a standard fused silica sample. The calibration was also conducted between measurements. Indentations were made directly into the films for various depths depending on the film thickness using the CSM. 
Raman micro-spectroscopy of the residual spherical and Berkovich indentations in the GeOI films were performed with a Bruker Senterra spectrometer (Bruker Optics, Germany) Raman microscope, Fig. 2(a) and 2(b). Figure 2(a) represents a Berkovich indent, whereas Fig. 2(b) represents a spherical indent. The Raman micro-spectroscopy measurements were done for all locations labeled 0-6 for both indents. We reported the results for the center location 0 for both indenters, locations 3 and 5 for the Berkovich indenter, and locations 1 and 4 for the spherical indenter.

It is anticipated that the central region will yield more accurate results due to the proximity of the maximum pressure induced by the very sharp tip of the indenter. An excitation laser of a wavelength $\lambda=785 \mathrm{~nm}$ operated at $10 \mathrm{~mW}$ was used. The laser was focused on a spot of $1 \mu \mathrm{m}$ diameter of the sample surface. An Olympus MPLAN $100 \times$ NA 0.8 objective was used for focusing the laser onto the sample surface and to imaging the indented spot
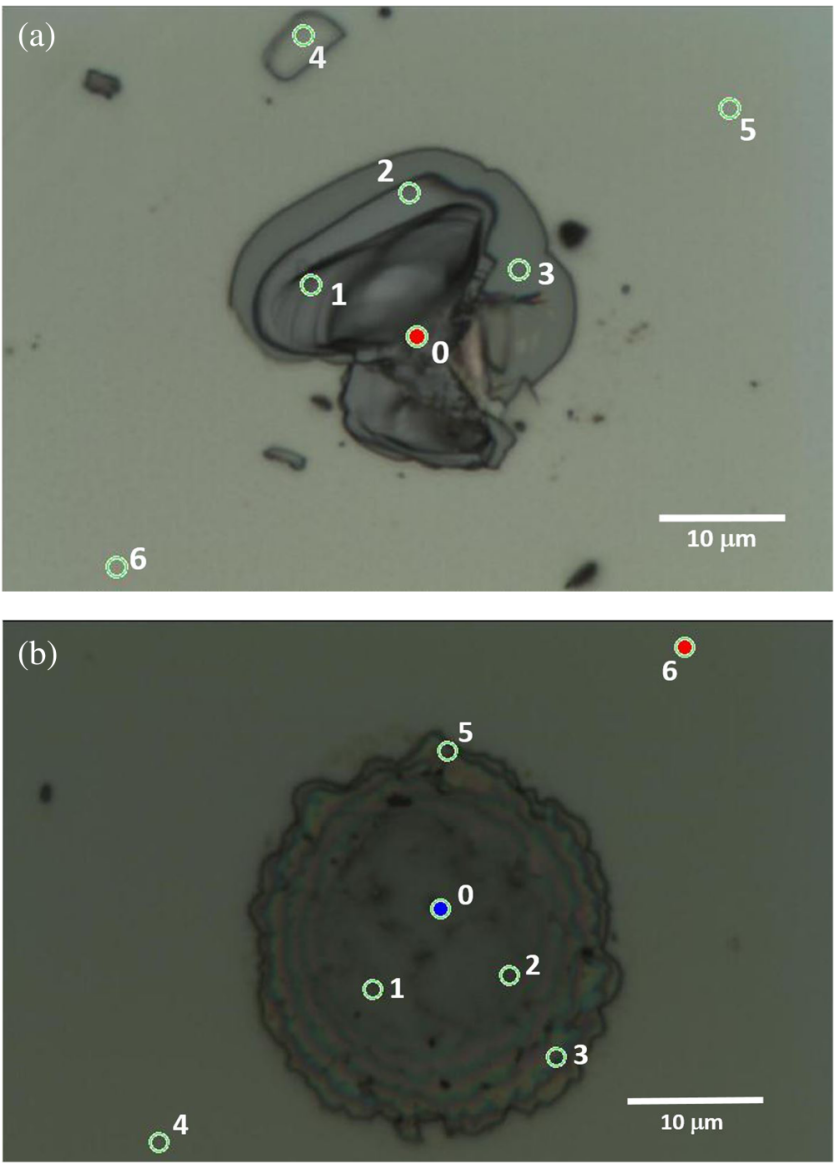

FIG. 2. (a) and (b) Optical microscopy photographs of spherical and Berkovich indents on $\mathrm{GeOl}$ films. Locations $0-6$ represent the positions where the Raman micro-spectroscopy measurements were performed for both indents. The results are reported for the center location 0 for both indenters, locations 3 and 5 for the Berkovich indenter, and locations 1 and 4 for the spherical indenter. The estimated beam diameter is $\sim 1 \mu \mathrm{m}$. illuminated by the excitation laser. Each spectrum was integrated over $40 \mathrm{~s}$ with two co-additions $(2 \times 20 \mathrm{~s})$. Spectra were recorded inside and outside the indents. The recording time of a single Raman spectrum was from a few seconds to several minutes, depending on the laser beam intensity and the probe material. Although, the Raman spectroscopy measurements were performed on both spherical and Berkovich indentations, the hardness and modulus results are only presented for the Berkovich indentations.

\section{RESULTS AND DISCUSSION}

Size effect studies conclude that surface properties are much higher than bulk for crystalline materials including electronic materials. The study by Liu et al. ${ }^{20}$ concluded that for Bulk Ge when the indentation depth exceeds $100 \mathrm{~nm}$, the hardness and elastic modulus of each crystal plane of the germanium single crystal decrease with the increase of the loading depth, which shows a significant indentation size effect. The study established that, for depth of indentations less than $70 \mathrm{~nm}$, the hardness and modulus are much higher than the properties at a deep depth of indentation, i.e., larger than $1 \mu \mathrm{m}$ for bulk Ge samples. This brings up a very important question here which is: suppose if we fabricate a thin film from the same material and test it will the property of the thin film mimic the property of the same bulk material at the surface? The electronic materials community believes that an extremely thin film fabricated from a semiconductor material such as Ge would be very flexible and can be rolled-up like a newspaper. This cannot happen if the properties of the film are similar to the properties of the bulk material at the surface. In the current study for GeOI thin films fabricated using the Smart Cut ${ }^{\mathrm{TM}}$ technology, we found out that $\mathrm{Ge}$ thin films with variable thicknesses exhibit properties similar to the properties of bulk Ge at deep indents. The Raman spectroscopy provided an in-sight of the nature of the spherical and Berkovich impressions on the GeOI surface. Spherical indents indicate bands of metastable Ge phases @ $220 \mathrm{~cm}^{-1}, 195 \mathrm{~cm}^{-1}$, and $184 \mathrm{~cm}^{-1}$ wavenumbers. Our results demonstrate that a spherical indenter impacted a wider area of contact and produced GeOI indented surfaces free of cracks and fracture. The spherical indenter tip kept the Ge top layer intact when compared to the Berkovich indenter tip during penetration. In contrast, the Berkovich indenter tip developed excessive fracture that resulted in displacing the $\mathrm{Ge}$ top layer sideways and exposed the Si substrate underneath revealing Raman spectra bands of metastable Si phases @ $350 \mathrm{~cm}^{-1}$, $399 \mathrm{~cm}^{-1}$, and $430 \mathrm{~cm}^{-1}$. ${ }^{21}$ The penetration depth of the excitation laser of a wavelength of $785 \mathrm{~nm}$ for $\mathrm{Si}$ is $>1 \mu \mathrm{m}$ and for $\mathrm{Ge}$ is $<1 \mu \mathrm{m} .{ }^{21}$ The measurements were performed at $\sim 6$ wavenumber spectral resolution.

The load-depth curves of the GeOI films are shown in Fig. 3. The data represent five indents from each film from a total of 16 indents per film. The total displacement into the surface was decided based on the film thickness to circumvent the substrate effect, i.e., for the $220 \mathrm{~nm}$ film, the total displacement into the surface was $\approx 55 \mathrm{~nm}$ with a projected indentation load of $\approx 0.6-0.7 \mathrm{mN}$. Similarly for the 250 and $290 \mathrm{~nm}$ films, the total displacements into the surface were $\approx 62$ and $72 \mathrm{~nm}$ with corresponding indentation loads of $\approx 0.8$ and $\approx 1.1 \mathrm{mN}$, respectively. The total depth of penetration of the indenter consists of an elastic portion 


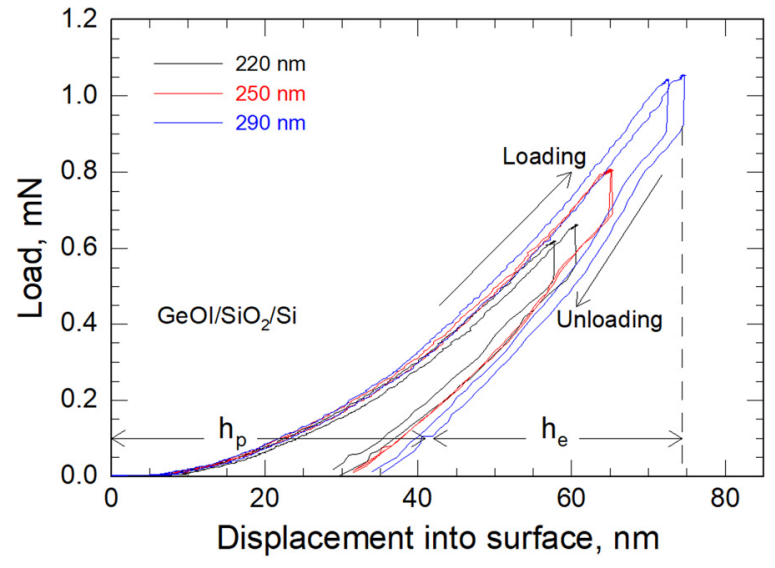

FIG. 3. Berkovich load-depth curves of $\mathrm{GeOl}$ films.

$h_{e}$ and a plastic portion $h_{p}$. The elastic displacement $h_{e}$ can be determined and subtracted from the total measured depth of penetration to yield the plastic depth $h_{p}$.

The elastic depth of indentation is given by

$$
h_{e}=L C \text {, }
$$

where $L$ is the load of indentation and $C$ is the unloading compliance which is given by

$$
C=\frac{1}{E_{\text {eff }} \sqrt{A}}+C_{m}
$$

where $C_{m}$ is the machine compliance and $E_{\text {eff }}$ is the effective modulus as given by Stone et al., ${ }^{22}$

$$
\frac{1}{E_{e f f}}=\frac{1-v_{s}^{2}}{\beta E_{s}}+\frac{1-v_{d}^{2}}{\beta E_{d}},
$$

where $E_{s}, v_{s}, E_{d}$, and $v_{d}$ are Young's moduli and Poisson's ratios for the specimen and indenter. $\beta$ is a constant.

A straight line is fitted to the unloading data between $85 \%$ and $95 \%$ of the load in Fig. 3. The measured unloading compliance, $C$, is determined from the load-depth curve as the inverse of the slope of the linear portion of the unloading data.

The contact area is given by

$$
\sqrt{A}=\frac{1}{E_{e f f}\left(C\left(h_{e}\right)-C_{m}\right)},
$$

and the hardness is determined using

$$
H=\frac{L}{A} .
$$

The load-depth curves of the 48 indents were virtually identical and the loading-unloading curves were traceable.
The hardness of the GeOI films is plotted vs the contact depth of indentation $\left(\mathrm{h}_{\mathrm{c}}\right)$ normalized to the film thickness $\left(h_{\text {film }}\right)$ in Fig. 4. The samples were tested at a depth of indentation to film thickness of $25 \%$ in order to measure the mechanical properties of the top single crystal $\mathrm{Ge}(100)$ film of the GeOI samples and circumvent the substrate effects. The hardness varies between 8 and $10 \mathrm{GPa}$ for the three different film thicknesses investigated. Liu et al. ${ }^{20}$ reported hardness results of 13.1, 17.4, and 14.6 GPa of bulk $\mathrm{Ge}(100), \mathrm{Ge}(110)$, and $\mathrm{Ge}(111)$ at a depth of indentation of $70 \mathrm{~nm}$, i.e., at the surface or hardness of surface layers of bulk Ge, respectively. ${ }^{20}$ These values are higher than the 8 and $10 \mathrm{GPa}$ of the Ge thin films of our GeOI samples. Lie et al., ${ }^{20}$ Gerk and Tabor, ${ }^{23}$ and Yonenaga ${ }^{24}$ reported hardness values between 7 and $8 \mathrm{GPa}$ for Bulk Ge at a deep depth of indentation. The results of bulk Ge (100) from Liu et al..$^{20}$ and Yonenaga ${ }^{24}$ are shown in Fig. 4 as well. The hardness of the bulk Ge at the surface, i.e., at a depth of indentation less than $70 \mathrm{~nm}$ are much higher than the hardness of the Ge thin film samples and we also observe that the hardness of the bulk Ge, i.e., at a deep depth of indentation correlate well with the hardness of the thin Ge films samples in this study. The difference in hardness between bulk Ge and single crystal thin films of Ge on top of the GeOI samples indicates that the fabrication process of the GeOI sample structure produced Ge films with improved properties as compared to the surface properties of the bulk Ge samples. As the top GeOI films become softer, it is unlikely that any electronic devices subsequent to their fabrication might encounter fatigue failure due to crack nucleation and propagation. On the contrary, since bulk Ge is more brittle in comparison to the GeOI films, it is anticipated that bulk Ge might experience fatigue failure due to crack nucleation and propagation. Similarly, the reported moduli values of 157,257 , and $190 \mathrm{GPa}$ for the $\mathrm{Ge}(100), \mathrm{Ge}(110)$, and $\mathrm{Ge}$ (111) bulk samples as reported by Liu et al. ${ }^{20}$ are considered higher

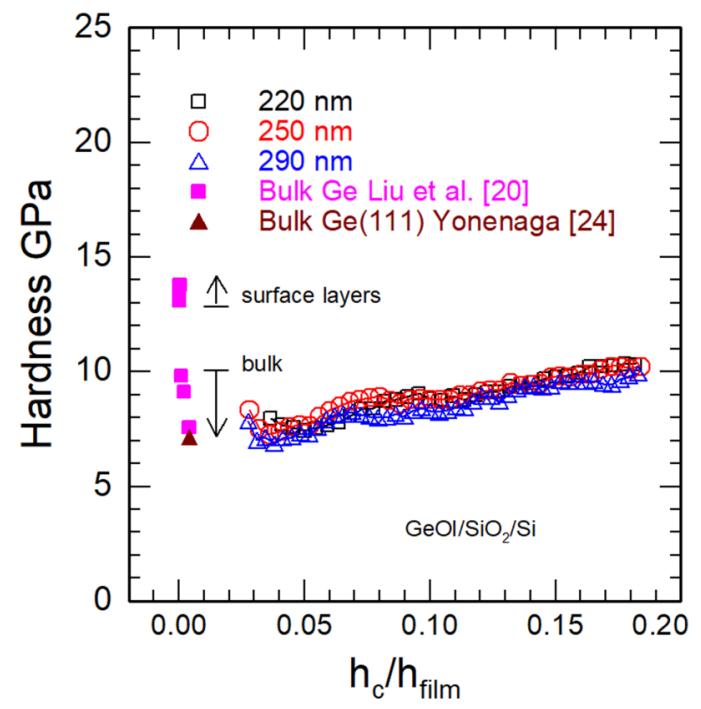

FIG. 4. Hardness of the GeOl films vs the contact depth of indentation $\left(h_{c}\right)$ normalized to the film thickness $\left(h_{\text {film }}\right)$. 


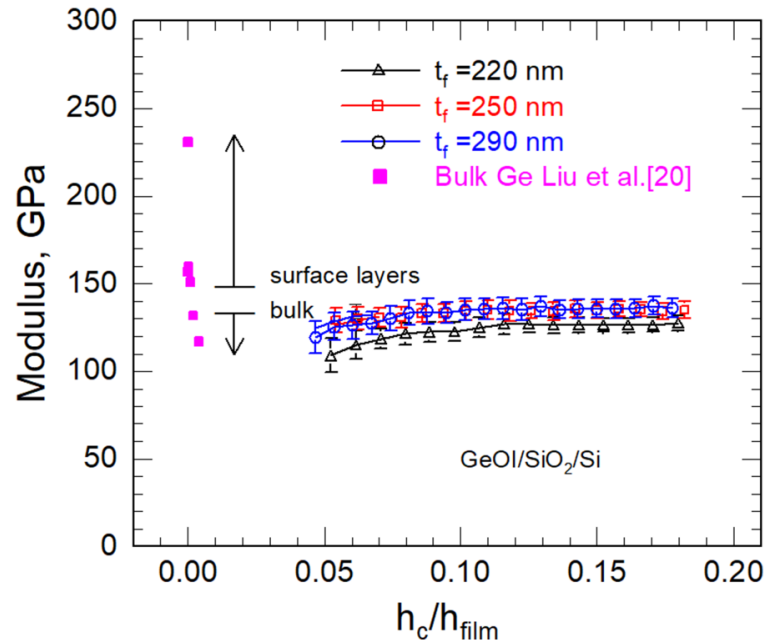

FIG. 5. Modulus of the $\mathrm{GeOl}$ films vs the contact depth of indentation $\left(h_{c}\right)$ normalized to the film thickness $\left(h_{\text {film }}\right)$.

than the moduli values for the three different film thicknesses which vary between 130 and $140 \mathrm{GPa}$ as shown in Fig. 5. Likewise, the moduli results of bulk $\mathrm{Ge}(100)$ from Liu et al., ${ }^{20}$ are also shown in Fig. 5. The moduli of bulk Ge measured at the surface for a depth of indentation less than $70 \mathrm{~nm}$ are also much higher than the moduli of the Ge thin film samples. We also note that the moduli of the bulk $\mathrm{Ge}$, i.e., at a deep depth of indentation correlate well with the moduli of the $\mathrm{Ge}$ thin films. This also indicates that bulk $\mathrm{Ge}$ at the surface is stiffer than the GeOI films, a property that might impede the fabrication of robust and more flexible devices from bulk Ge. Therefore, single crystal GeOI thin films with improved mechanical properties provide an alternative route for electronic devices fabrication compared to bulk Ge. The use of Raman spectroscopy demonstrates induced metastable phases in both the $\mathrm{Si}$ substrate underneath the buried oxide and the Ge top film for the Berkovich and spherical indentations respectively, Fig. 6. The spectra of metastable phases of Si @ wavenumbers of 350,399, and $430 \mathrm{~cm}^{-1}$, resulting from the Si substrate underneath were detected for the Berkovich indentations, where the sharp pyramid tip routinely pierced the Ge top film and the buried oxide to expose the bulk $\mathrm{Si}$ substrate. However, an intense $\mathrm{Si}$ band was detected at $520 \mathrm{~cm}^{-1}$, whereas a weak $\mathrm{Ge}$ is observed at a wavenumber of $300 \mathrm{~cm}^{-1}$. Using the Berkovich diamond indenter tip is accompanied by excessive cracks in the films beneath the indenter tip that caused the Ge top layer to be displaced sideways ${ }^{25}$ as in Fig. 6. From Fig. 6, we observed that several metastable $\mathrm{Si}$ and $\mathrm{Ge}$ phases were exposed at location 0 at the center of the Berkovich and spherical indentations where the maximum pressure is exerted by each indenter tip. The Berkovich indents revealed metastable Si phases@ $350 \mathrm{~cm}^{-1}, 399 \mathrm{~cm}^{-1}$, and $430 \mathrm{~cm}^{-1}$, whereas the spherical indents depicted metastable Ge phases@ @220 cm $\mathrm{cm}^{-1}, 195 \mathrm{~cm}^{-1}$, and $184 \mathrm{~cm}^{-1}$ wavenumbers, respectively. The scans of locations 3 (slightly off-centered) and 5 (outside the indent) for the Berkovich indenter illustrated the presence of strong $\mathrm{Si}$ phase at $520 \mathrm{~cm}^{-1}$ and a weak $\mathrm{Ge}$ peak at $300 \mathrm{~cm}^{-1}$

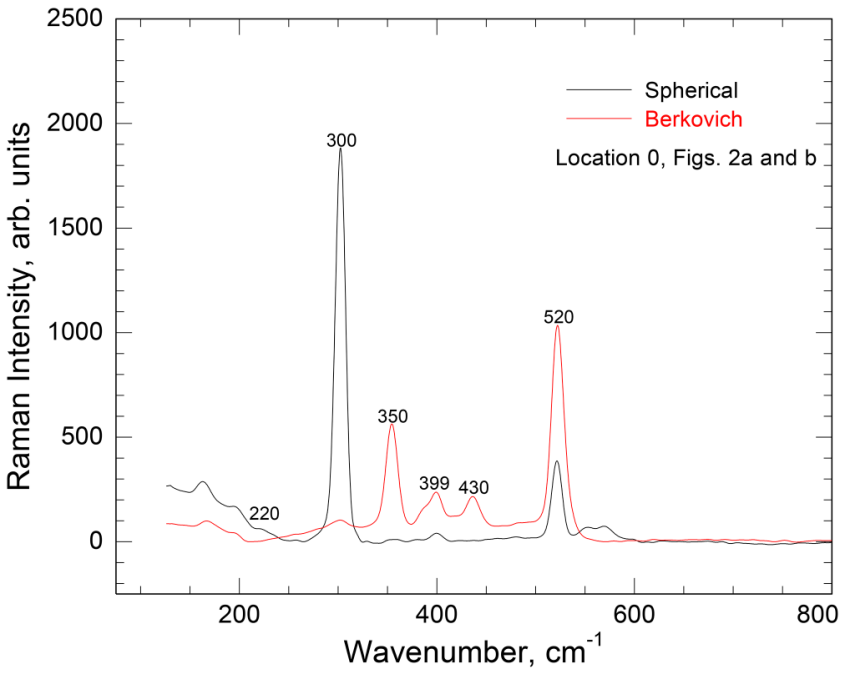

FIG. 6. Raman spectroscopy of induced metastable phases of $\mathrm{Si}$ and $\mathrm{Ge}$ for the Berkovich and spherical indentations represented by locations 0 of Figs. 2(a) and 2(b), respectively.

wavenumbers as shown in Fig. 7. Similarly, as expected, for the spherical indenter, a strong Ge phase at $300 \mathrm{~cm}^{-1}$ and a weak $\mathrm{Si}$ peak at $520 \mathrm{~cm}^{-1}$ wavenumbers for locations 1 (slightly off-centered) and 4 (outside the indent) were detected as shown in Fig. 8.

In contrast, only the spherical indenter tip did not shatter the single crystal Ge top film and allowed micro-Raman spectra to focus on the intact $\mathrm{Ge}$ film indicating bands of metastable $\mathrm{Ge}$ phases@ wavenumbers of 220,195, and $184 \mathrm{~cm}^{-1}$ in comparison

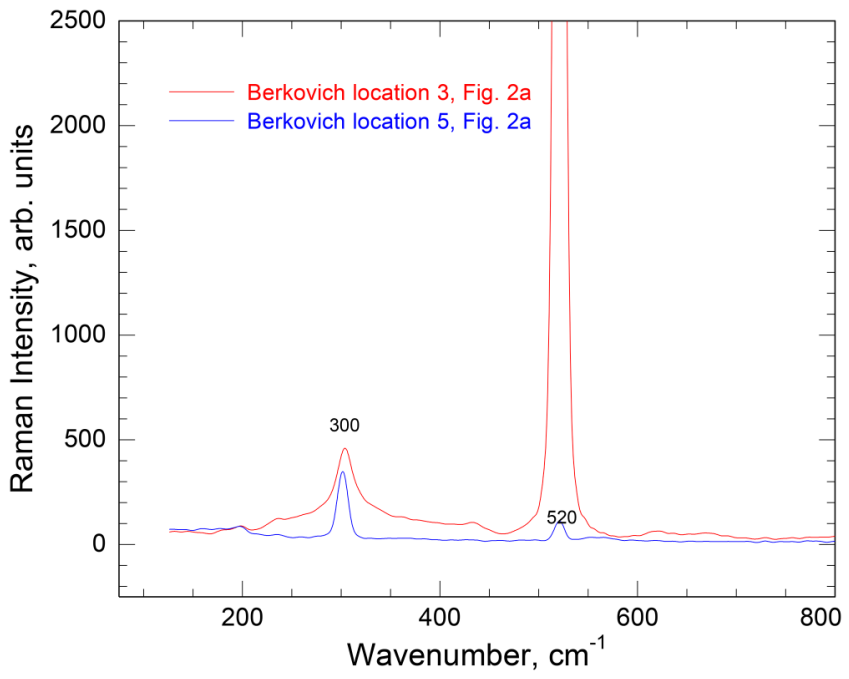

FIG. 7. Raman spectroscopy of induced phases of Si and Ge for the Berkovich indentations represented by locations 3 and 5 of Fig. 2(a). 


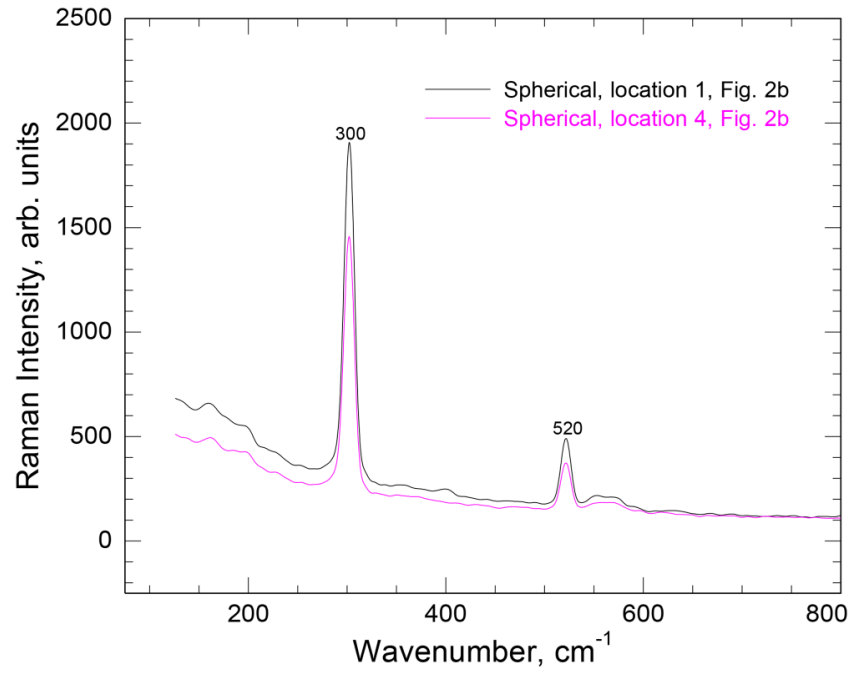

FIG. 8. Raman spectroscopy of induced phases of $\mathrm{Si}$ and Ge for the spherical indentations represented by locations 1 and 4 of Fig. 2(b).

to a wavenumber of $300 \mathrm{~cm}^{-1}$ of bulk Ge subjected to a bi-axial tensile strain. ${ }^{26}$ The Raman peak around $300 \mathrm{~cm}^{-1}$ wavenumbers corresponds to the longitudinal optical (LO) phonon in Ge. A weak Si band @ $520 \mathrm{~cm}^{-1}$ wavenumbers is observed and a strong Ge band @ $300 \mathrm{~cm}^{-1}$ is evident. From the images of Fig. 2, with less fracture and cracks, the spherical indenter tip covers a wider area of contact which caused the top Ge layer to remain intact as compared to the Berkovich indenter tip, which breaks up and shatters the Ge film.

\section{CONCLUSION}

Our results demonstrate that the nanomechanical properties of perfect defect-free single crystal Ge films on top of the GeOI composite samples fabricated using the Smart Cut ${ }^{\mathrm{TM}}$ technology and film exfoliation are significantly different from the results of bulk Ge obtained by Liu et al., ${ }^{20}$ and SOI films results obtained by Miller et al. ${ }^{19}$ From our measured hardness results of 8 to $10 \mathrm{GPa}$ for very thin single crystal $\mathrm{Ge}(100)$ films compared to $13.1 \mathrm{GPa}$ for surface layers of Bulk $\mathrm{Ge}(100)$, one can conclude that the mechanical properties of the thin Ge films are comparable to the properties of bulk $\mathrm{Ge}$ at a deep depth of indentation. Similarly, our measured modulus of 130 to $140 \mathrm{GPa}$ for thin $\mathrm{Ge}(100)$ films compared to the reported bulk $\mathrm{Ge}(100)$ value of $157 \mathrm{GPa}$ corroborates these research findings.

The Raman spectroscopy of the Berkovich indents indicates spectra bands of metastable phases @ 350,399, and $430 \mathrm{~cm}^{-1}$ wavenumbers of the exposed $\mathrm{Si}$ substrate underneath the buried oxide.

The Berkovich indenter tip developed excessive fracture that resulted in displacing the Ge top layer sideways. This result demonstrates that the sharp pointed Berkovich indenter tips produced excessive cracks and cause fracture of the Ge film and hence exposing the underlying bulk Si substrate. The spherical indents spectra indicate bands of metastable Ge phases @ wavenumbers of 220, 195 , and $184 \mathrm{~cm}^{-1}$. The Ge top layer remains intact because the spherical indenter tip impacts a wider area of contact due to less fracture and cracks as compared to the Berkovich indenter tip.

Finally, apart from the well documented electrical advantages of $\mathrm{GeOI}$, the reported research on the nanomechanical properties reveals considerable softening and flexibility of the very thin Ge films that promise added benefits and further implications for enhancing potential device applications of $\mathrm{GeOI}$ wafers for process integration.

\section{DATA AVAILABILITY}

The data that support the findings of this study are available from the corresponding author upon reasonable request.

\section{REFERENCES}

${ }^{1}$ T. Akatsu, J.-M. Hartmann, A. Abbadie, C. Aulnette, Y.-M. LeVaillant, D. Rouchon, Y. Bogumilovicz, L. Portigliatti, C. Colnat, N. Boudou, F. Lallement, F. Triolet, C. Figuet, M. Martinez, P. Nguyen, C. Delattre, K. Tsyganenko, B. Berne, F. Allibert, and C. Deguet, ECS Trans. 3(6), 107-117 (2006).

${ }^{2}$ C. Mazure and A.-J. Auberton-Herve, "Engineering wafers for the nanotechnology era," in Proceedings of 31st European Solid-State Circuits Conference (ESSCIRC 2005) (IEEE, 2005), pp. 29-38.

${ }^{3}$ T. A. Langdo, M. T. Currie, Z.-Y. Cheng, J. G. Fiorenza, M. Erdtmann, G. Braithwaite, C. W. Leitz, C. J. Vineis, J. A. Carlin, A. Lochtefeld, M. T. Bulsara, I. Lauer, D. A. Antoniadis, and M. Somerville, Solid-State Electron. 48, 1357 (2004).

${ }^{4}$ I. Cayrefourcq, A. Boussagol, and G. Celler, "Wafer-level stress in combination with process induced stress for optimum performance enhancement," ECS Trans. 3(7), 399 (2006).

${ }^{5}$ Y. S. Li and J. Nguyen, Sci. Rep. 8, 16734 (2018).

${ }^{6}$ T. K. P. Luong, V. L. Thanh, A. Ghrib, M. El Kurdi, and P. Boucaud, Adv. Nat. Sci. Nanosci. Nanotechnol. 6, 015013 (2015).

${ }^{7}$ A. K. Okyay, A. Nayfeh, K. C. Saraswat, T. Yonehara, A. Marshall, and P. C. McIntyre, Opt. Lett. 31, 2565 (2006).

${ }^{8}$ S.-i. Kobayashi, Y. Nishi, and K. C. Saraswat, Thin Solid Films 518(6), S136 (2010).

${ }^{\mathbf{9}}$ T. Akatsu, C. Deguet, L. Sanchez, F. Allibert, D. Rouchon, T. Signamarcheix, C. Richtarch, A. Boussagol, V. Loup, F. Mazen, J.-M. Hartmann, Y. Campidelli, L. Clavelier, F. Letertre, N. Kernevez, and C. Mazure, Mater. Sci. Semicond. Process. 9, 444 (2006).

${ }^{10} \mathrm{C}$. Claeys and E. Simoen, Extended Defects in Germanium Fundamental and Technological Aspects (Springer, Berlin, 2009). eBook Packages Chemistry and Materials Science Print, ISBN: 978-3-540-85611-5, online ISBN: 978-3-540-85614-6, series Print ISSN: 0933-033X, series online ISSN: 2196-2812. ${ }^{11}$ S. Minomura and H. G. Drickamer, J. Phys. Chem. Solids. 23, 451 (1962).

${ }^{12}$ J. C. Jamieson, Sci. New Series 139(3556), 762 (1963).

${ }^{13}$ M. S. R. N. Kiran, B. Haberl, J. E. Bradby, and J. S. Williams, Semicond. Semimetals 91, 165 (2015).

${ }^{14}$ Y. G. Gogotsi, V. Domnich, S. N. Dub, A. Kailer, and K. G. Nickel, J. Mater. Res. 15, $871(2000)$

${ }^{15}$ J. E. Bradby, J. S. Williams, J. Wong-Leung, M. V. Swain, and P. Munroe, Appl. Phys. Lett. 80, 2651 (2002).

${ }^{16}$ J. Jang, M. J. Lance, S. Wen, and G. M. Pharr, Appl. Phys. Lett. 86, 131907 (2005).

${ }^{17}$ D. J. Oliver, J. E. Bradby, J. S. Williams, M. V. Swain, and P. Munroe, J. Appl. Phys. 101, 043524 (2007).

${ }^{18}$ D. Tabor, Nature 273, 406 (1978). 
${ }^{19} \mathrm{~N}$. Miller, K. Tapily, H. Baumgart, G. K. Celler, F. Brunier, and A. A. Elmustafa, in Surface and Interfacial Nanomechanics, edited by R. F. Cook, W. Ducker, I. Szlufarska, and R. F. Antrim (Mater. Res. Soc. Symp. Proc., Warrendale, PA, 2007), Vol. 1021E, 1021-HH05-24.

${ }^{\mathbf{2 0}}$ N. Liu, X.-J. Yang, Z. Yu, and L. Zhao, Trans. Nonferrous Met. Soc. China $\mathbf{3 0}$, 181 (2020).

${ }^{21}$ W. S. Yoo, K. Kang, T. Ueda, T. Ishigaki, H. Nishigaki, N. Hasuike, H. Harima, M. Yoshimoto, and C. S. Tan, ECS J. Solid State Sci. Technol. 4(2), P9-P15 (2015).
${ }^{22}$ D. S. Stone and K. B. Yoder, J. Mater. Res. 9, 2524 (1994).

${ }^{23}$ A. P. Gerk and D. Tabor, Nature 271, 732 (1978).

${ }^{24}$ I. Yonenaga, Mater. Trans. 46(9), 1979 (2005).

${ }^{25}$ A. Kailer, K. G. Nickel, and G. Gogotsi, J. Raman Spectrosc. 30, 939 (1999).

${ }^{26}$ A. Gassenq, K. Guilloy, G. Osvaldo Dias, N. Pauc, D. Rouchon, J.-M. Hartmann, J. Widiez, S. Tardif, F. Rieutord, J. Escalante, I. Duchemin, Y.-M. Niquet, R. Geiger, T. Zabel, H. Sigg, J. Faist, A. Chelnokov, V. Reboud, and V. Calvo, Appl. Phys. Lett. 107, 191904 (2015). 